\title{
Editorial \\ The role of the paediatric nurse
}

For referencing Parry YK. The role of the paediatric nurse. Journal of Children and Young People's Health 2021; 2(2):3

DOI https://doi.org/10.33235/jcyph.2.2.3

\section{Dear readers}

I have the privilege of welcoming you to the second edition of the Journal of Children and Young People's Health (JCYPH). We know, as paediatric nurses, that our work in supporting infants, children, young people and their families is ongoing, and now the impact of COVID-19 has added to our workload. We are also aware that the number of children in Australia is steadily increasing and are projected to reach 5.2 million in 2038. Therefore, the significance of our role within the healthcare system - and our workloads - are set to increase.

The resilience and challenges we have faced during COVID-19 have highlighted not only the uniqueness of our role as paediatric nurses on the front-line but also the immense pressure created within health delivery. There is now an acknowledgment of the impact of burnout, depression, compassion fatigue and secondary traumatic stress faced by many of our colleagues, and this has been researched extensively in recent times. The role of bringing into focus our unique skills, dedication and work is important. This work is supported by our collegiality and connections through ACCYPN and the JCYPH.

The ACCYPN webinars, conference and the JCYPH are central to representing and acknowledging the great work we do. Paediatric nursing is a rewarding profession that provides a vast plethora of services across a myriad of health settings. Our recent virtual conference and webinars provide valuable insights into the roles of paediatric nurses and the rewarding opportunities for service and health delivery. The diversity of our roles and research is captured in the wide variety of presentations at the conference, in our webinars and in the journal articles presented today. In addition, the interdisciplinary nature of our work and research is evident in the articles we provide here, the conference presentations and our webinars. In the coming months and years, the numbers of paediatric nurses will increase; thus, valuing what we do, and expanding our evidence-based practice and research dissemination, is paramount to our future resilience and success.

I look forward to your next article submission.

Best wishes Yvonne

\section{Yvonne K Parry}

PhD, MHSM, GradCertEdu (Higher Education), BA

(Psychology \& Public Policy), RN

Editor, JCYPH

Board of Directors, Australian College of Children and

Young People's Nurses

Chair, Credentialling Committee Australian College of

Children and Young People Nursing

Senior Lecturer and PG Course Coordinator

Flinders University, VIC 